\title{
Student and Teacher Attitudes as Correlates of Performance in Mathematics in Cameroon Secondary Schools
}

\author{
Tamukong Ndifor Mariana Ngeche, Ph.D* \\ Researcher, Chief of Service for Studies and In-Service Training, Government Teacher Training College \\ (GTTC-ENIEG) Limbe, Cameroon.
}

\begin{abstract}
*Corresponding Author: Dr. Tamukong Ndifor Mariana Ngeche, Ph.D, Researcher, Chief of Service for Studies and In-Service Training, Government Teacher Training College (GTTC-ENIEG) Limbe, Cameroon.
\end{abstract}

\begin{abstract}
This study examined the relationship between student attitudes and performance in Mathematics in secondary schools in Cameroon. The study employed a descriptive research design of the survey type. The population consisted of all the secondary school students in the North West region of Cameroon. The purposive sampling technique was used to select 40 secondary schools and the simple random sampling technique was used to select 400students from the selected schools. A self -structured instrument tagged "Student Performance Questionnaire (SPQ)" which was validated by research experts in Curriculum Studies was used to collect data for the study. The data collected was analysed using simple percentages and the Pearson Product Moment Correlation. The study generally revealed a significant relationship between student attitudes and performance in Mathematics. Specifically, it revealed that the cognitive, affective and behavioural attitudes of students influence their performance in Mathematics. Based on the findings of the study, it was recommended that students should endeavour to build new mathematical knowledge through problem solving and apply and adapt a variety of appropriate strategies to solve problems. Considering that teachers' attitude predicts student attitudes toward performance in mathematics, it was recommended that the subject "Didactics of Mathematics" be taught as a compulsory subject for all teacher training institutions. Also, routine capacity building workshops should be organised at the national, regional and school levels to develop the cognitive, affective and behavioural attitudes of in-service teachers.
\end{abstract}

Keywords: Students and Teacher Attitudes, Correlates of Performance and Mathematics

\section{INTRODUCTION}

The knowledge of mathematics is an essential tool in every society (Baroody, 1987). It is a tool that can be used in our daily life to overcome the difficulties faced (Bishop, 1996). Due to this mathematics has been considered as one of the most important core subject in a school curriculum. More mathematics lessons are likely to be taught in schools and colleges throughout the world than any other subject (A. Orton, D. Orton, \& Frobisher, 2004). However, the standard tests and evaluations reveal that students do not perform to the expected level. The student under achievement in mathematics is not just a concern for particular countries, but has become a global concern over the years (Pisa, 2003).Most countries regard mathematics as the foundation for scientific and technological knowledge which is a very important instrument for political, socio-economic, scientific and technological development (Nekang, 2016). Mathematics is one of the compulsory subjects recommended by the General Certificate of Education (GCE) Board at the first Cycle. This decision is in line with the government's emergence vision through problem solving. Problem solving has long been recognized as one of the hallmarks of Mathematics. The problem solving competences gained in the study of Mathematics is used in all spheres of human life(Billstein, Libeskind and Lott, 2004).The building of problem solving competences in Mathematics is hindered by attitudes. Attitude is concerned with an individual's way of thinking, acting and behaving. Negative and positive attitudes are formed throughout the learning experiences students undergo (Yara, 1999). Teacher attitudes and beliefs play a pivotal role in shaping classroom practices in general and students performance in 
particular (Bolhuis \&Voeten, 2004).Research studies have concluded that, most Mathematics teachers are impatient, unfriendly, coercive and limit their teaching to computation. These attitudes sometimes depict negative dispositions that induce tendencies of fear, anxiety and stress in students (HarborPeters, 2001). Previous studies have indicated a significant relationship between student attitude and performance in Mathematics in other countries but this study examines the topic in Cameroon.

\section{BACKGROUND TO THE STUDY}

Several studies and researches have been done in many countries to examine the factors that influence students' performance in mathematics. Among these factors, students' attitudes towards mathematics are one important factor that has been consistently studied. Often, the studies on relationship between students' attitudes and the students' academic performance show a positive relationship (Mohd, Mahmood, \& Ismail, 2011). Students' attitudes towards mathematics are a major factor that might influence the performance of the students. Several studies have been conducted in different countries to find out students' attitudes towards mathematics (Tahar, Ismail, Zamani \& Adnan, 2010; Tezer \& Karasel, 2010). Data collected and analysed suggested that the low performance of students in Mathematics is influenced by attitude factors. The research focused on students' attitudes towards mathematics and also finding the significant difference between students' attitude towards mathematics with regard to gender of the students.

The competence gained in the study of Mathematics is widely used in all spheres of human life. Mathematics plays a key role in shaping how individuals deal with the various spheres of private, social, and civil life (Anthony \& Walshaw, 2009). This justifies the compulsion of the study of the subject by all students who go through basic and secondary education in most countries. Mathematics is therefore a core subject at these levels of education in Cameroon. It is regrettable, therefore, that in the contemporary times many students struggle with Mathematics and perform abysmally low in their final examinations in most jurisdictions. In Cameroon, students' performance in Mathematics at the High School has not been encouraging of late. Candidates are reported to exhibit poor understanding of Mathematical concepts and are unable to form the appropriate Mathematical models which could be tackled with the requisite skills. It has also been realised that many students have developed negative attitude towards the study of Mathematics as a result of mass failure of students in the subject. It is an irrefutable fact that the successfulness of learning the subject is contingent on myriad of factors. School, classroom, student and teacher factors all impinge on the learning of Mathematics. In particular, the seriousness or otherwise importance attached to the teaching of Mathematics invariably affects students' performance in their final examinations.

Educational researchers have expended time and energy trying to unravel the possible causes of students' poor attitudes and performance in Mathematics. An area that has not been explored extensively is the influence of teacher attitudes on student attitudes towards the study of the subject. Research findings indicate that effective teachers facilitate learning by truly caring about their students' engagement and creating the right atmosphere that enhances student learning (Noddings, 1995). They have high yet realistic expectations about enhancing students' capacity to think, reason, communicate, reflect upon and critique their own practice, and they provide students with opportunities to ask why the class is doing certain things and with what effect (Watson, 2002). The relationships that develop in the classroom become a resource for developing students' attitudes and Mathematical competencies and identities. These resources are very essential to the learning of Mathematics.

Attitude as a concept is concerned with an individual's way of thinking, acting and behaving. It has very serious implications for the learner, the teacher, the immediate social group with which the individual learner relates, and the entire school system. Attitudes are formed as a result of some kind of learning experiences students go through. This is mimicry, which also has a part to play in the teaching and learning situation. In this respect, the learner draws from his teachers' disposition to form his own attitude, which may likely affect his learning outcomes (Yara 2009). Yara (2009) avers that teachers with positive attitude towards Mathematics were inclined to stimulate favourable attitudes in their pupils. This immediately puts the teacher in the spotlight as one whose attitude, expressed in their behaviour, has a telling effect on students. Teachers' attitude and beliefs play a very significant role in shaping classroom practices (Bolhuis \& Voeten, 2004). Does teacher attitude 
towards teaching significantly predict student attitude towards the learning of Mathematics and enhance students' achievement? Evidence of the relationship between teacher attitude and student attitude towards Mathematics have been anecdotal hence the need to undertake this study for practical evidence.

\section{Statement of the Problem}

Mathematics is important as a means of finding a way out of difficulty, a way round an obstacle and attaining an aim which is not immediately attainable. Unfortunately in Cameroon, students' performance in Mathematics at sequential evaluations is catastrophic. The highest number of absences and failed grades are recorded in Mathematics in all certificate examinations. Such performances can be likened to the attitudes of the students towards Mathematics. The problem of this study therefore, is to find out whether students' attitudes can influence their performance in Mathematics.

\section{OBJECTIVES OF THE STUdY}

Generally, the study sought to find out whether student attitudes influences their performance in Mathematics. Specifically, it examined the relationship between:

- Student and teachers cognitive attitude and performance in Mathematics

- Student and teachers affective attitude and performance in Mathematics

- Student and teachers behavioural attitude and performance in Mathematics

\section{RESEARCH HYPOTHESES}

To attain the objectives of the study, the following hypotheses were formulated:

- There is no significant relationship between student and teachers cognitive attitudes and performance in Mathematics.

- There is no significant relationship between student and teachers affective attitudes and performance in Mathematics.

- There is no significant relationship between students and teachers behavioural attitudes performance in Mathematics.

\section{CONCEPTUAL AND THEORETICAL REVIEW}

Components of Attitude Research suggest that there are three different components of attitude. These are the cognitive component, the affective component, and the behavioural component (Eagly \& Chaiken, 1993; Maio \& Haddock, 2010). The cognitive component of attitude is what the individual thinks or believes about the attitude object. An example is that a person might think that a snake is a dangerous reptile. The affective aspect of attitude is the feelings or emotions of the individual associated with the attitude object. For example, the sight of a snake may evoke the feeling of fear in the individual. The behavioural component is the tendency to respond in a certain way to the attitude object. An example is a person choosing to run away or scream upon seeing a snake. Hence the cognitive, affective and behavioural components of attitude are interrelated and interconnected.

Formation of Attitude Research has shown that formation of attitude is experiential. People form attitudes through their experiences in life. Social psychology explains how attitudes are formed using three major learning theories which are classical conditioning, operant conditioning and observational learning. Propounded by Ivan Pavlov, classical conditioning is a procedure for modifying behaviour in which repeated pairing of conditioned stimulus with an unconditioned stimulus leads to the development of a conditioned response (Ntim, 2010, Linero \& Hinojosa, 2012). Classical conditioning entails neutral stimuli that naturally elicit a response. Children, for instance, become fans of football clubs of their fathers. They grow up believing that those particular football clubs are the best and develop the same passion for the clubs. Hence, we form attitudes according to how we are conditioned or how our experiences condition us. B.F. Skinner's Operant Conditioning theory is a form of learning in which a response is made in anticipation of a stimulus. In operant conditioning, reinforcement increases the likelihood that behaviour will be repeated (Ntim, 2010). Behaviours that are followed by positive consequences are reinforced and are more likely to be repeated than are behaviours and attitudes that are followed by negative consequences (Moris \& Maisto, 2001). Operant 
conditioning requires the use of reinforcement and punishment. A case in point is if a child's mother smiles at her anytime she picks something up for her, the child begins to realise that it is good to be helpful and she is likely to repeat the behaviour. Conversely, if a mother screams at a child for picking up a puff of a piece of cigarette, the child will grow up having an unfavourable attitude towards smoking and probably those who smoke. This is due to the negative consequence of her action.

Finally, people also learn attitude through observation of people around them, especially if they are people they admire, respect or hold in high esteem. Children therefore invariably observe the attitude of parents and teachers and learn a lot from them. Observational learning theory propounded by Albert Bandura posits that behaviours are acquired by watching another or the model that performs the behaviour (Yara, 2009). The model displays the behaviour and the learner observes and tries to imitate it. Teachers are, invariably, role models whose behaviours are easily copied by students.

\subsection{Attitude towards Mathematics}

Some authorities regard attitude towards Mathematics as just a like or dislike for Mathematics, while others extend the meaning to embrace beliefs, ability, and usefulness of Mathematics. For Zan and Martino (2007), attitude towards Mathematics is just a positive or negative emotional disposition towards Mathematics. Neale (1969), however, defines attitude towards Mathematics as an aggregated measure of "a liking or disliking of Mathematics, a tendency to engage in or avoid Mathematical activities, a belief that one is good or bad at Mathematics, and a belief that Mathematics is useful or useless". Similarly, Hart (1989) considers attitude towards Mathematics from multidimensional perspectives and defined an individual's attitude towards Mathematics as a more complex phenomenon characterised by the emotions that he associates with Mathematics, his beliefs about Mathematics and how he behaves towards Mathematics. Attitude towards Mathematics includes the tendency to be fearful of and anxious about Mathematics. Attitude towards Mathematics has cognitive, affective and behavioural components; and like any other kind of attitude, it can be formed through any of the three processes described earlier. A student can develop positive attitude towards Mathematics because he or she learns to associate positive experiences or events with it. Also, positive reinforcement creates room for the formation of positive attitude for Mathematics. And by no means is students' observation of teachers and teachers' behaviour especially in relation to Mathematics among the least of the factors that influence their attitude towards Mathematics.

\subsection{Student Attitude towards Mathematics}

The conceptions, attitudes, and expectations of students regarding Mathematics and Mathematics teaching have been considered to be very significant factors underlying their school experience and achievement (Borasi, 1990; Shoenfeld, 1985). In general, the concepts students hold about Mathematics determine how they approach the subject. In many cases, students have been found to approach Mathematics as procedural and rule oriented. This prevents them from experiencing the richness of Mathematics and the many approaches that could be used to develop competence in the subject. Attitude can also be gender related. There are many who hold the view that boys do better in Mathematics than girls. This belief tends to affect the attitude of girls towards Mathematics. Farooq and Shah (2008) in a study of secondary school students in Pakistan found that there was no significant difference in confidence of male and female students towards Mathematics at secondary school level. They rather found that students' success in Mathematics depended on attitude towards the subject. Nonetheless, some studies have found gender difference in students' confidence in Mathematics. Compared to boys, girls lacked confidence, had debilitating causal attributional patterns, perceived Mathematics as a male domain and were anxious about Mathematics (Casey, Nuttal \& Pezaris, 2001). In the study, girls were found to have lower self-confidence in Mathematics than boys.

Instructively, research on the relationship between student attitude and performance has also been inconclusive. Researches that have been conducted to determine the relationship between students' attitude towards Mathematics and achievement in Mathematics have yielded contradictory results. The findings have thus lacked consistency on the subject. Some studies have demonstrated a strong and significant relationship between Mathematics attitude and Mathematics achievement (Minato \& Yanase, 1984, Randhawa \& Beamer, 1992, Schenkel, 2009). In the Schenkel's (2009) study of elementary school pupils, positive correlation between student attitude and student performance was 
found. Student beliefs and attitudes were found to have the potential to either facilitate or inhibit learning. In a comparative study of factors influencing Mathematics achievement, Burstein (1992) found that there is a direct link between students' attitudes towards Mathematics and student outcomes. Cheung (1998), in his study of 11-13 year olds, also discovered positive correlation between attitude and Mathematics achievement. The correlation showed that the more positive the attitude, the higher the level of achievement in the student. Some researches have, however, demonstrated that the correlation between attitude towards Mathematics and achievement in Mathematics was rather weak and could not be considered to be of practical significance (Vachon, 1984; Wolf \& Blixt, 1981). In a meta-analysis of 113 primary studies involving elementary and secondary school children, Ma and Kishor (1997) found that attitude towards Mathematics and achievement in Mathematics was positively and reliably correlated but not strong. The correlation was not statistically significant. Flowing from the preceding findings, studies in different cultural settings are eminent to realise the influence of student attitude towards Mathematics on student learning outcomes in the subject.

\subsection{Teacher Attitude towards Mathematics}

An understanding of how attitudes are learned should establish a connection between teachers and students' attitudes, and attitudes and performance. Schofield (1981) reports that positive teacher attitude towards Mathematics was significantly related to high achievement in pupils. Bridget, Vemberg, Twemlow Fonag, and Dill (2008) studied how the teachers' attitude contributed to students' academic performance and behaviour. The study unveiled, among other things, that students with more devoted teachers were regarded by their peers as helpful to victims of bullying relative to students with less devoted teachers. The study also disclosed that students with the devoted teachers had the courage and determination to face difficulties in school life. Teachers were recognised as those who provided support, encouraged students and their value for love eradicated unwanted behaviour in students. Teachers are, invariably, role models whose behaviours are easily copied by students. What teachers like or dislike, appreciate and how they feel about their learning or studies could have a significant effect on their students. Unfortunately however, many teachers seldom realize that how they teach, how they behave and how they interact with students can be more paramount than what they teach (Yara, 2009).

Like all other kinds of attitude, a teacher's attitude towards Mathematics can be measured by the emotional response towards Mathematics (affective), beliefs about Mathematics (cognitive), as well as behaviour. Clarke, Thomas and Vidakovic (2009) postulate that attitudes and practices of teaching Mathematics are complexly affected by beliefs, emotions, social context and content knowledge. Studies confirm that emotional responses toward Mathematics that are found in teachers include like and dislike of Mathematics, anxiety associated with Mathematics and self-confidence in relation to Mathematics (Phillipou \& Christou, 1998, Brady \& Bowd, 2005, Henderson \& Rodrigues, 2008). These emotional factors have been found to have an impact on student performance. In their study of teachers' self-esteem connected to Mathematics, Henderson and Rodrigues (2008) found that approximately half of the participating pre-service teachers, some of whom were highly qualified, lacked self-esteem in relation to Mathematics. Burks, Heidenburg, Leoni and Ratliff (2009) stipulate that teachers' exhibition of self-confidence when teaching Mathematics motivates student achievement in Mathematics. The learner draws from the teacher's disposition to form his own attitude which may affect her learning outcomes.

Teachers' beliefs about Mathematics such as the usefulness of Mathematics, the way Mathematics should be learned, the difficulty or ease of Mathematics, as well as gender ability and beliefs also affect their attitude towards the subject and impact on students' performance. According to Philippou and Christou (1998), teachers' beliefs about the utility of Mathematics are often found to correlate with either a more positive or negative attitude towards the subject. It is believed that a teacher who sees no usefulness of Mathematics in the real world and believes that Mathematics should be learnt as a set of rules and algorithms will require his students to memorise procedures and rules without meaning. This is a negative outlook that will make his students develop a negative attitude towards the subject. Also, a teacher who believes that girls are poor in Mathematics is likely to impact negatively on girls in his class who will begin to believe that they cannot do Mathematics.

Another aspect of the teacher's attitude towards Mathematics is the teacher's behaviour in relation to Mathematics. Such Mathematics-related behaviour as avoidance of Mathematics, pursuit of 
Mathematics and instructional behaviour in the classroom all affect student attitude and performance. Usually, the way that Mathematics is represented in the classroom and perceived by students, even when teachers believe they are presenting it in authentic and context dependent way stands to alienate many students from Mathematics (Barton, 2000, Furinghelti \& Pekhoren, 2002). Ogunniyi, as cited in Yara, (2009) stipulates that students' positive attitude towards Mathematics is enhanced by the following teacher-related factors: teachers' enthusiasm, teachers' resourcefulness and helpful behaviour and teachers' thorough knowledge of the subject-matter and their making Mathematics quite interesting. It is inferred that teachers can foster in students the positive attitudes about Mathematics that help to build confidence by: encouraging the belief that everyone can "do" Mathematics - emphasizing effort, not innate ability; modelling enthusiasm for teaching and learning Mathematics; addressing the learning styles of students by providing a variety of ways for students to gain an understanding of difficult concepts; helping students to appreciate the value of Mathematics in their lives; and choosing activities carefully (not too easy, not too hard), so that students can be both challenged and successful (Ministry of Education, Ontario (2004).

\section{REVIEW OF RELATED LITERATURE}

Attitude is a central part of human identity. Everyday people love, hate, like, dislike, favour, oppose, agree, disagree, argue, persuade etc. All these are evaluative responses to an object. Hence attitudes can be defined as ,a summary evaluation of an object of thought ${ }^{\text {e }}$ (Bohner \& Wänke, 2002). They are inclinations and predispositions that guide an individual's behaviour (Rubinstein, 1986) and persuade to an action that can be evaluated as either positive or negative. Attitudes develop and change with time (Rubinstein, 1986). According to Multicomponent model of Attitude (Eagly \& Chaiken, 1993), attitudes are influenced by three components. They are cognitive (beliefs, thoughts, attributes), affective (feelings, emotions) and behavioural information (past events, experiences) (G. Maio, G. R. Maio, \& Haddock, 2010). When reviewing literature on students' attitude towards mathematics, it reveals that several factors play a vital role in influencing student's attitude. These factors can be categorised into three distinctive groups. Firstly, factors associated with the students themselves. Some of these factors include student's mathematical achievement score (Köğce et al, 2009), anxiety towards mathematics, student's self-efficacy and self-concept, extrinsic motivation (Tahar et al, 2010) and experiences at high school.

Secondly, the factors that are associated with the school, teacher and teaching. Some of these factors that influence attitudes are teaching materials used by teacher, teachers' classroom management, teachers' content knowledge and personality, teaching topics with real life enriched examples, other student's opinions about mathematics courses (Yilmaz, Altun \& Olkun, 2010), teaching methods, reinforcement (Papanastasiou, 2000), receiving private tuition (Köğce et al, 2009), teachers' beliefs towards mathematics (Cater \& Norwood, 1997) and teachers' attitude toward mathematics.

Thirdly, factors from the home environment and society also affect students' attitude towards mathematics. Factors such as educational background of parents, occupation of parents (Köğce et al, 2009) and parental expectations (Tobias, 1993) play a crucial role in influencing students' attitude towards mathematics. Due to these several factors students have different attitude towards mathematics. More often, the public image of mathematics is labelling it as a difficult, cold, abstract, theoretical and ultra-rational subject (Ernest, 2004). However, some studies show that students have a relatively positive attitude towards mathematics (Tezer \& Karasel, 2010; Yilmaz et al, 2010; Fan, Quek, Yan, Mei, Lionel \& Yee, 2005). Sometimes, Mathematics is also considered as very important and largely masculine subject (Ernest, 2004). Several studies gives evidence that compared to boys, girls lack confidence in doing mathematical sums and viewed mathematics as a male domain (Meelissen \& Luyten, 2008).

However there are many studies that suggest that there is no significant difference between attitudes towards mathematics among male and female students (Mohd et al, 2011;). And there are some other studies which suggest that the attitudes of the participants of their study towards mathematics was more positive in the third year than the first year (Grootenber \& Lowrie, 2002) and there is a difference between attitudes in the grades 6,7 and 8 (Köğce et al, 2009). Hence it can be said that students' attitudes towards mathematics are very subjective and varies among the students. Several studies had been conducted to find out the relationship between attitudes towards mathematics and 
academic achievement of the students. Most of these studies showed that there is a positive correlation between students' attitudes towards mathematics and academic achievement (Mohd et al, 2011) and also achievement in problem solving (Nicolaidou \& Philippou, 2003), The studies have also shown that students' attitudes towards problem solving in terms of patience, confidence and willingness has a positive relation with students' mathematics achievement (Mohd et al, 2011).

Student attitudes have given rise to varied perceptions about Mathematics. Firstly, they perceive that the subject involves formulas and computations. Secondly, it is difficult and thirdly, it is male dominated (Santrock, 2004; Casey, Nuttal\&Pezaris, 2001). Some studies have demonstrated a strong and significant relationship between student attitudes and high performance in Mathematics (Schenkel, 2009; Minato \&Yanase, 1984; Randhawa \& Beamer, 1992). Student attitudes are inversely influenced by teachers' attitudes. For example teachers who do not bully, make the students see value in learning the subject, teach from simple to complex, believe the class is not a one-size-fit-alland teach Mathematics from practice and not computation, students will develop a positive attitude towards the subject. Yara (2009) established a positive relationship between teacher attitude and student attitude towards Mathematics.

\section{Methodology}

The descriptive research design of the survey type was adopted in this study. The population of the study consisted of 40 public secondary schools in the North West region of Cameroon. The first stage involved the use of purposive sampling to select 40 secondary schools. The second stage involved the use of the simple random sampling technique to select 400 Form 1-5students from the selected schools. A self -structured questionnaire tagged "Student Performance Questionnaire (SPQ)" was validated by research experts in Curriculum Studies were used to collect data for the study. Sections A, sought background information of the respondents, Sections B, contained 5 items each designed to elicit information on attitudes and Sections $\mathrm{C}$ had 5 items each designed to collect information on performance.The items on the questionnaire was of the Likert type. The instruments were validated by research experts in the areas of curriculum studies and test done in the seven divisions that make up the population of the study. The face validity of the instrument was ascertained through peer review. Test-retest method of reliability was adopted for SPQ while percentages were used to determine reliability which stood at 95\%. The data for the study were analysed using the SPSS version 16 for descriptive and inferential statistics. The hypotheses formulated were tested at 0.05 alpha level.

\section{RESULTS AND DISCUSSION}

In analysing the extent of student performance, Section A SPQ, percentages were used to analyse the responses on items 1-12 to determine student performance considering the attitude of the teacher. The result is presented on Table 1 .

Table 1. Extent of Student Performance

\begin{tabular}{|l|c|c|c|}
\hline \multicolumn{1}{|c|}{ Variable } & Positive & Negative & Total \\
\hline Student attitude & $67.5 \%$ & $22.5 \%$ & 100 \\
\hline Total & $\mathbf{6 7 . 5 \%}$ & $\mathbf{2 2 . 5 \%}$ & $\mathbf{1 0 0}$ \\
\hline
\end{tabular}

To test the hypotheses, correlation coefficient was computed using Pearson Moment Correlation Coefficient. Correlation between student cognitive attitude and performance was computed and the results are displayed in Table 2.

Table 2. There is no significant relationship between student cognitive attitudes and performance in Mathematics

\begin{tabular}{|l|l|}
\hline Correlation & $1.24 * * *$ \\
\hline Pearson Correlation & 0.008 \\
\hline Significance (2 tailed) & 400 \\
\hline $\mathrm{N}$ & \\
\hline
\end{tabular}

The test of the hypothesis at 0.05 significance level revealed a significant Pearson Correlation Coefficient value of 1.24. The results show a positive and significant relationship between student cognitive attitude and performance. Therefore the null hypothesis is rejected and it is concluded that a significant positive relationship exist between student cognitive attitude and performance in Mathematics. This affirms Borasi (1990) assertion that students cognitive attitude influences their performance in Mathematics positively. 
Table 3: There is no significant relationship between student affective attitudes and performance in Mathematics

\begin{tabular}{|l|l|}
\hline Correlation & $1.676^{* * *}$ \\
\hline Pearson Correlation & 0.000 \\
\hline Significance (2 tailed) & 400 \\
\hline $\mathrm{N}$ & \\
\hline
\end{tabular}

The test of the hypothesis at 0.05 significance level revealed a significant Pearson Correlation Coefficient value of 1.676. The results show a positive and significant relationship between student affective attitude and performance. Therefore the null hypothesis is rejected and it is concluded that a significant positive relationship exist between student affective attitude and performance in Mathematics. This supports the findings of Chueng (1998) that student's affective attitude influences their performance in Mathematics significantly. Where students develop feelings of anxiety or fear in learning Mathematics, their ability to learn and enjoying the lesson reduces tremendously.

Table 4. There is no significant relationship between student behavioural attitudes and performance

\begin{tabular}{|l|l|}
\hline Correlation & $3.516^{* * *}$ \\
\hline Pearson Correlation & 0.06 \\
\hline Significance (2 tailed) & 400 \\
\hline $\mathrm{N}$ &
\end{tabular}

The test of the hypothesis at 0.05 significance level revealed a significant Pearson Correlation Coefficient value of 3.516. The results show a positive and significant relationship between student behavioural attitude and performance. Therefore the null hypothesis is rejected and it is concluded that a significant positive relationship exist between student behavioural attitude and performance in Mathematics. This affirms Henderson \& Rodrigues (2008) assertion that students behavioural attitude in Mathematics is positively influenced by the teacher's behaviour.

\section{CONCLUSiON AND RECOMMENDATIONS}

The study has disclosed that the attitudes of students significantly influences their performance in Mathematics. This implies that teachers as facilitators in the teaching/learning process must do all that it takes to build cognitive, affective and behavioural competences in students as far as the learning of Mathematics is concerned. Positive correlations have been found between student cognitive, affective and behavioural attitudes and student performance in Mathematics. The teacher's attitudes is pivotal in modifying student attitudes towards the learning of Mathematics. It is therefore important that:

- Students build new mathematical knowledge through problem solving and apply and adapt a variety of appropriate strategies to solve problems

- Students monitor and reflect on the processes of mathematical problem solving.

- Students solve problems in small mixed ability groups using cognitive behaviours and processes that are very similar to those of expert mathematical problem solvers.

- Teachers are taught the Didactics of Mathematics while in training and attend capacity building workshops for continuous professional development. Above all, they should exhibit positive behaviours towards the subject Mathematics.

The study has disclosed that the attitudes of the Mathematics teachers were related to the attitude of the students towards the subject. A significant relationship was found between teacher attitude and student attitude towards Mathematics. This connotes that irrespective of the Mathematical capability of students if teachers display negative attitude towards Mathematics students may not develop positive attitude towards the subject and vice versa.

The positive attitude of Mathematic teachers towards the subject, the positive the students' attitude towards the study of the subject. The attitude of the teacher resonates in the attitude of her students toward the subject. Teachers' attitude towards Mathematics, therefore, matters as it has a powerful influence on student attitude formation. The positive correlation between students' attitude and students' performance, and teacher attitude and students' performance in Mathematics further demonstrate that attitude plays a central role in student learning. Particularly, teachers' attitude toward teaching Mathematics is seen as an important factor in the formation of students' attitude towards the 
learning of the subject. Mathematics teachers can therefore positively influence students' attitude towards Mathematics by demonstrating positive attitude towards the teaching of the subject in class.

It is, therefore, important and imperative for Mathematics teachers to develop positive attitude towards the subject and make Mathematics interesting and appealing to students in order to help them develop a positive attitude towards it. Mathematics teachers ought to create interesting and nonthreatening environments in their Mathematics classroom and model enthusiasm for the teaching and learning of the subject. This may go a long way to help students develop positive attitude towards the subject, learn it without any inhibition and hence improve their performance.

\section{REFERENCES}

[1] AEC Clarke, P. A. J., Thomas, C. D. and Vidakovic, D. (2009). Pre-service Mathematics teachers' attitudes and developing practices in urban classroom: Are they "winging" it? Research and Practice in Social Science, 5(1), 22-43.

[2] Anthony, G., and Walshaw, M. (2009). Characteristics of effective teaching of Mathematics: A view from the West. Journal of Mathematics Education, 2(2), 147-164.

[3] Arul, M. (1995). Characteristics of effective teaching of Mathematics. Journal of Mathematics Education. 2(2) $146-164$.

[4] Barton, A. C. (2000). Crafting multicultural science education with pre-service teachers through servicelearning. Journal of Curriculum Studies, 32(6), 797-820.

[5] Billstein, R., Libeskind, S. and Lott, W. (2004). A problem solving approach to Mathematics. New York: Pre-Press Company.

[6] Bolhuis, S. and Voeten, J. M. (2004). Teachers' conception of student learning and own learning: Teachers and teaching, Theory and Practice, 10(1), 77-98.

[7] Bolhuis, S. and Voeten, J.M. (2004). Teacher's conception of student learning and own learning: Teachers and teaching, Theory and Practice, 10(1), 77-98.

[8] Borasi, R. (1990). The invisible hand operating on Mathematics instruction: Students' conceptions and expectations. Teaching and learning mathematics in the 1990s (NCTM Yearbook), 174-182.

[9] Brady, P., and Boyd, A. (2005). Mathematics anxiety, prior experience and confidence to teach mathematics among pre-service education students. Teachers and Teaching: Theory and Practice, 11(1), 37-46.

[10] Burstein, L. (1992). The analysis of multilevel data in educational research and evaluation. Review of Research in Education; 8, 158-223.

[11] Casey, M. B., Nuttal, R. L. and Pezaris, F. (2001). Spatial-mechanical reasoning skills versus Mathematics self-confidence as mediators of gender differences on Mathematics subtests. Journal of Research in Mathematics Education, 32(1), 28-57.

[12] Casey, M., Nuttal. R. and Pezaris, F. (2001). Spatial-mechanical reasoning skills versus Mathematics selfconfidence as mediators of gender differences on Mathematics subtests. Journal of Research in Mathematics Education, 32(1), 28-57.

[13] Cheung, K. (1998). Outcomes of Schooling: Mathematics achievement and attitudes towards mathematics learning in Hong Kong. Educational Studies in Mathematics, 19(2), 209-219.

[14] Cheung, K. C. (1998). Outcomes of Schooling: Mathematics achievement and attitudes towards mathematics learning in Hong Kong. Educational Studies in Mathematics, 19(2), 209 - 219. Chief Examiners' Report, WASSCE (2007). The West African Examinations Council, 2007. Accra: W

[15] Eagly, A. and Chaiken, S. (1993). The Psychology of Attitudes. Orlando: Harcourt Brace Jovanovich College Publishers.

[16] Eagly, A. H., and Chaiken, S. (1993). The Psychology of Attitudes. Orlando: Harcourt Brace Jovanovich College Publishers

[17] Farooq, M. S. and Shah, S. Z. U. (2008). Students' attitude toward Mathematics. Pakistan Economic and Social Review, 48(1), 75-83

[18] Harbor-Peters, V. (2001). Inaugural lecture. Unmasking some aversive aspects schools mathematics and strategies for averting them : Enugu: Snaap Press.

[19] Henderson, S. and Rodrigues, S. (2008). Scottish Student Primary Teachers' Levels of Mathematics Competence and Confidence for Teaching Mathematics: Some implications for national qualifications and initial teacher education. Journal of Education for Teaching: International Research and Pedagogy, 34 (2). 93-107. 
[20] Mato, M. and De la Torre, E. (2010). Evaluation of the influence of attitudes on performance in Mathematics. PNA Vol. 5, no 1, pp 197-208

[21] Minato, S. and Yanase, S. (1984). On the relationship between student attitude towards school mathematics and their levels of intelligence. Educational Studies in Mathematics, 5, 12-320.

[22] Nekang, F. (2016). Principles and practice of mathematics education in Cameroon. Yaounde: NEC Cameroon.

[23] Nicolaidou, M. and Phillipou, G. (2003). Attitudes towards mathematics, self-efficacy and achievement in problem solving. European Research Journal in Mathematics Education III. Pp 1-11. University of Pisa, Italy.

[24] Nuttal, F. and Pezaris, S. (2001). How attitudes form change and shape our behaviour. Free psychology newsletter, About,com.

[25] Randhawa, B. and Bearmer, J. (1992). Gender similarities in a structural model for Mathematics achievement. Unpublished manuscript, University of Saskatchewan, Saskatoon, Canada

[26] Reed, S., Bergemann, E. and Olson, W. (1998). In the Classroom: An introduction to education. New York: McGraw Hill.

[27] Santrock, J. (2004). Educational Psychology: $2^{\text {nd }}$ Ed. New York: McGraw Hill.

[28] Schenkel, B. (2009). The impact of attitude toward mathematics performance. Unpublished MA Thesis, Mariette College.

[29] Smith, B. and Regan, K. (1999). Re-thinking Characteristics and beliefs in Mathematics. Journal of Education for Teaching: International Research Pedagogy. 32(2). 93-107.

[30] Yara, P. (2009). Relationship between teachers' attitude and students' academic achievement in Mathematics in some selected Senior Secondary Schools in South-western Nigeria. European Journal of Social Sciences. 11(3), 364-369.

[31] Zan, R. and Martino, P. (2007). Attitudes towards Mathematics: Overcoming positive/negative dichotomy. The Montana Mathematics Enthusiasts Monograph, 3 157-168

\section{AUTHORS BIOGRAPHY}

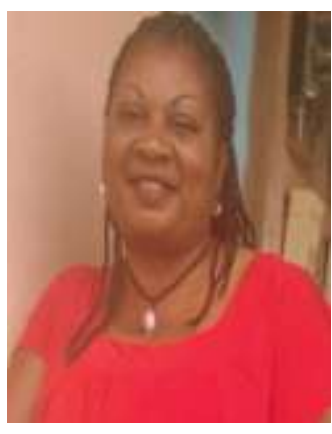

Dr. Tamukong Ndifor Mariana Ngeche currently is the Chief of Service for Studies and in-service Training in Government Teacher Training College (GTTC) Limbe and a part time lecturer in the Department of Administrative Techniques at the Higher Technical Teacher Training College (HTTTC) Kumba of the University of Buea. She worked as a Senior Staff "cadre d'etudes "at the Divisional Delegation of National Education Lebialem, Divisonal Delegation of Basic Education Fako, taught at GTTC Mamfe and GTTC Limbe. Dr. Tamukong has a degree in Private Law "Licence en Droit Prive" from the University of Yaoundé, she is a graduate from the Ecole Normale Superiure (ENS) de Yaoundé where she obtained the "Diplome de Professeur de 1'enseignement Normale 2e Grade" (DIPEN II). Dr. Tamukong has a Master of Education (M.Ed) Degree in Educational Foundations and Administration and a Ph.D. in Educational Foundations and Administration from the Cameroon prestigious University of Buea.

Dr. Tamukong Ndifor Mariana is a renowned Researcher consultant working with the: Foundation of Scientific Research, Community Based Rehabilitation and Advocacy on Inclusive Education" (FORCAIE-Cameroon). She has published articles in local and international journals and attended many seminars and presented workshop papers on diverse areas in education including planning, nursery education, primary education and teacher education. She is married with four (4) children. Dr. Tamukong Ndifor Mariana is a Research Consultant of Educational Planning and Administration, Nursery, Primary and Teacher Education, Educational policy and Financing.

Citation: Dr. Tamukong Ndifor Mariana Ngeche, Ph.D. " Student and Teacher Attitudes as Correlates of Performance in Mathematics in Cameroon Secondary Schools" International Journal of Humanities Social Sciences and Education (IJHSSE), vol 4, no. 12, 2017, pp. 1-10. doi: http://dx.doi.org/10.20431/23490381.0412001 .

Copyright: (C) 2017 Authors. This is an open-access article distributed under the terms of the Creative Commons Attribution License, which permits unrestricted use, distribution, and reproduction in any medium, provided the original author and source are credited. 